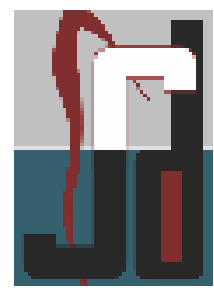

CASE SERIES

\title{
Mucogingival Aesthetic Surgery For An Isolated Denuded Root : A Complete Root Coverage Procedure
}

\author{
Sai Anusuya $\mathrm{G}^{1}$, Jacob Raja S.A², Joann Pauline George ${ }^{3}$, Johnson Raja J ${ }^{4}$
}

\begin{abstract}
Gingival augmentation coronal to the recession (root coverage) has become an important treatment modality because of increasing cosmetic and functional demands. In the selection of treatment procedures factors such as depth and width of gingival recession, availability of donor tissue, tooth position, root prominence, presence of muscle attachments and aesthetics has to be taken into consideration. A 25-year old male patient presented with Miller class II gingival recession in tooth no 33. His main concern was unpleasant elongated tooth appearance. Lateral pedicle graft root coverage procedure was selected and complete root coverage was obtained (favourable prognosis) with excellent prognostic scoring.
\end{abstract}

Key words : gingival recession, mucogingival aesthetic surgery, root coverage, lateral pedicle graft.

\section{INTRODUCTION}

Gingival recession is the apical migration of marginal gingiva, exposing the root surface to the oral environment ${ }^{1}$. More than $50 \%$ of the population has one or more sites of gingival recession $\geq 1 \mathrm{~mm}$, commonly involved being the buccal surface of the tooth ${ }^{2}$. Understanding the different stages and conditions of gingival recession is necessary for predictable root coverage. The predictability of root coverage can be enhanced by the presurgical examination and the correction of the recession by using the classification proposed by Miller ${ }^{4}$. Also there are several other factors that may also account for this unpleasant and unaesthetic effect like plaque induced gingival inflammation, lack of attached gingiva, malpositioned tooth, shallow vestibule or local iatrogenic factors ${ }^{3}$.

The laterally (horizontally) displaced pedicle flap technique ${ }^{9}$, originally described by Grupe and Warren (1956), was the standard technique for many years and is still indicated in some cases. This technique can be used to cover isolated denuded root surfaces that have adequate donor tissue laterally. The vestibular depth should also be sufficient ${ }^{4}$.

The present case report describes a case of mucogingival aesthetic root coverage of an isolated gingival recession in mandibular canine by employing lateral pedicle graft technique.

\section{CASE REPORT}

A 25-year old healthy male patient presented to the Department of Periodontology, Krishnadevaraya College of Dental Sciences and Hospital, Bangalore, Karnataka, India with a chief complaint of unpleasant elongatedtooth appearance of corner tooth in the lower jaw. Patient had a non-contributory medical history. Intraoral examination revealed a Miller's localized grade II gingival recession (Figure 1) in relation to the lower left mandibular canine (33) measuring $3 \mathrm{~mm}$ in height and $2 \mathrm{~mm}$ in width (Figure 2). There was an adequate attached gingiva $(4 \mathrm{~mm})$ present in relation to 34 . Adequate vestibular depth was also observed. Intraoperative periapical radiograph revealed no interdental bone loss in 33, 34 regions. Trauma from occlusion and tooth malposition in respect to the involved tooth was ruled out clinically.

Before root coverage was attempted the exposed portion of the root should be rendered free from bacterial plaque. Through scaling and root planning (Figure 3) was done and the patient was periodically recalled to assess his oral hygiene before planning periodontal surgical procedure. The positive compliance from the patient was assessed and inform consent was taken before performing surgical root coverage procedure.

Root prominence with respect to 33 was reduced (Figure 4). Root conditioning using tetracycline 
removes an amorphous surface layer and exposes the dentin tubules. Here the denuded root surface with respect to 33(Figure 5) was rubbed with tetracycline $\mathrm{HCl}(100 \mathrm{mg} / \mathrm{ml}$ for $3-5 \mathrm{~min})$.

The surgical site 33, 34 regions were anaesthetized with local anaesthesia (2\% lignocaine with 1:80,000 adrenaline). With a 15no.surgical blade, an internal bevel incision was given around denuded root of 33, to remove the adjacent epithelium and connective tissue (Figure 6). An external bevel incision was given starting from the mesial surface of 33 to expose the connective tissue surrounding the denuded root surface of 33 .

Donor site was prepared by extending sulcular incisions (Figure 7) from the distal surface of 33 to the mesial surface of 35. Two vertical incisions were made, one at distal line angle of 33 and other at mesial line angle of 35. Vertical incisions were made continuous with horizontal incisions, and were extended apically to the mucosal tissue topermit adequate flap mobility (Figure $8,9)$. The flap was raised using a sharp dissection. A cutback releasing incision (Figure 10)was made to ensure that the flap is free of tension and free enough to permit movement to the recipient site. The pedicle flap was positioned $1 \mathrm{~mm}$ coronal to cement-enamel junction of tooth 33 and immobilized with interrupted sutures using 3-0 Ethicon sutures (Figure 11, 12).

The donor site was covered with aluminium foil and a soft periodontal dressing(Figure 13,14). The patient was instructed regarding post-operative care of the surgical site. Analgesics and antibiotics were prescribed for days. Patient was instructed not to brush on the surgical

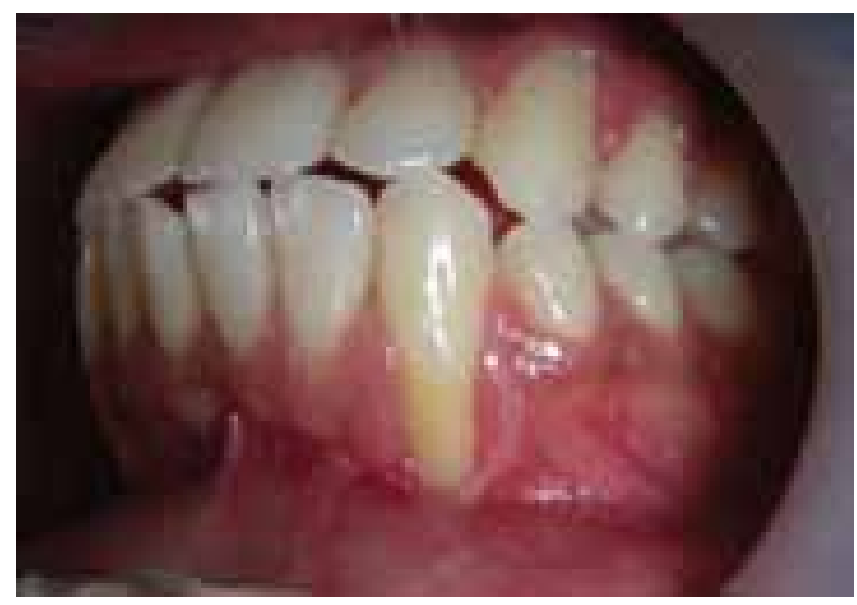

Fig.1: Pre Operative area and use chlorhexidinr gluconate $0.2 \%$ twice daily for 2 to 3 weeks. Sutureswere removed after 10 days of surgery. Following removal of the dressing and the sutures, the patient is instructed to avoid mechanical tooth cleaning for further 2 weeks, but to use twice daily rinsing with a chlorhexidine solution as a means of infection control.

Examination of surgical site showed complete coverage of root surface of 33 (figure 15, 16) with excellent colour matching. Patient was completely satisfied with the treatment outcome. Oral hygiene instructions were reinforced, and the patient was instructed to come for regular dental check-up.

\section{CLINICAL OUTCOME OF ROOT COVERAGE PROCEDURES ${ }^{5}$}

Independent of the modality of surgical procedure used to obtain soft tissue root coverage, shallow residual probing depth, gain in clinical attachment, and an increase in gingival height are the common characteristics of treatment outcome. Although the major indication for performing root coverage procedures is aesthetic/ cosmetic demands by the patient, few studies have included assessment of aesthetics as end-point of success.

A systematic review by Pagliaro et al (2003) gave a summary with regard to the average amount of initial Miller class I-II recession defects that was successfully covered following treatment; shows that an average of $63-86 \%$ root coverage may be expected. Complete coverage of the recession defect is the ultimate goal of the therapy.

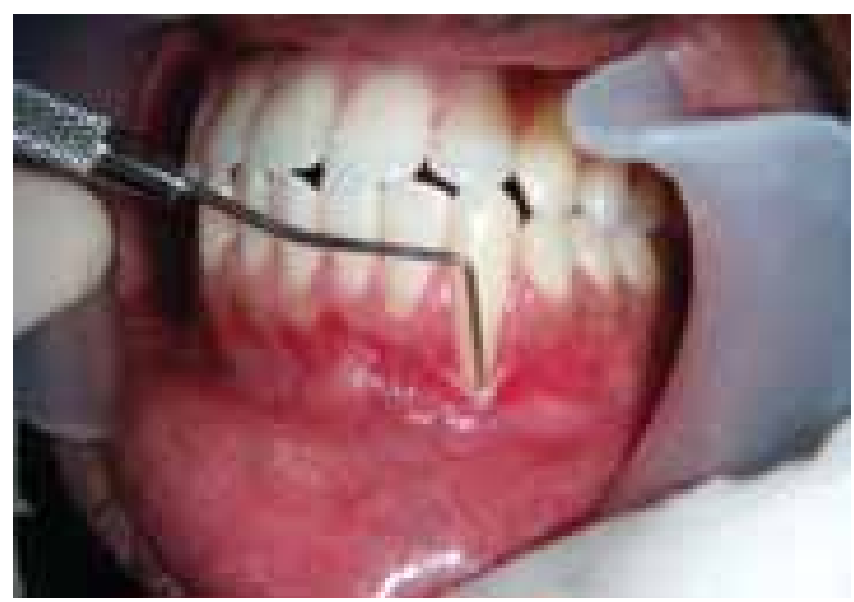

Fig. 2a: Height and width of gingival recession determined 


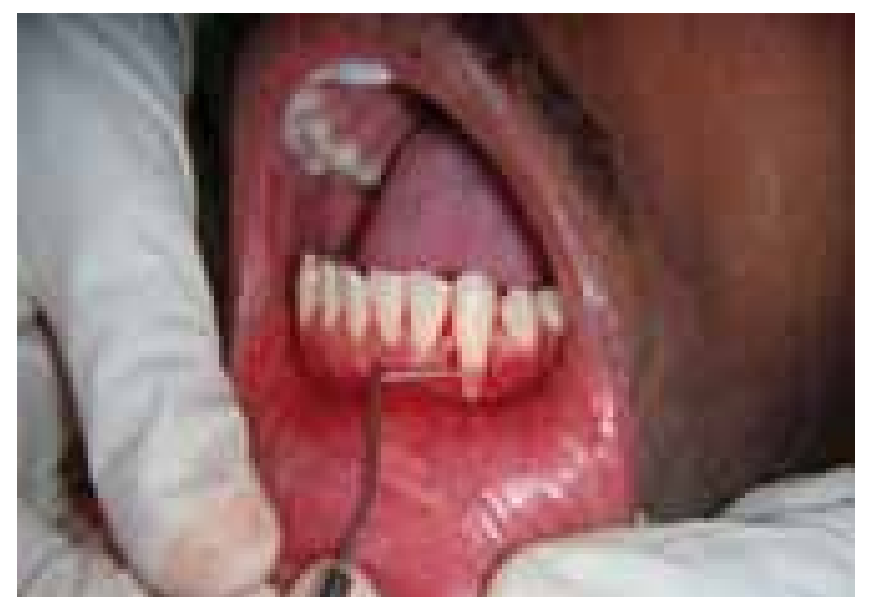

Fig. 2a: Height and width of gingival recession determined

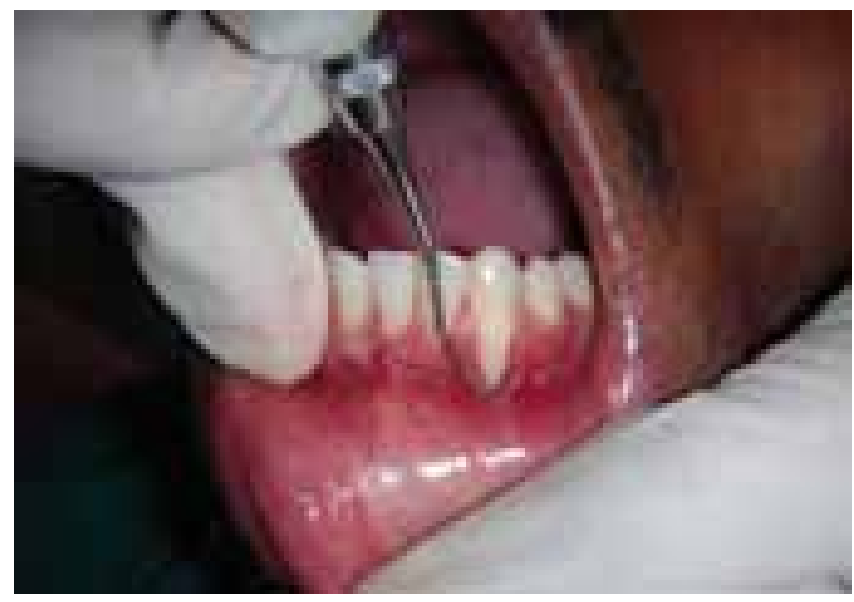

Fig.3 Scaling \& Root Planing Done

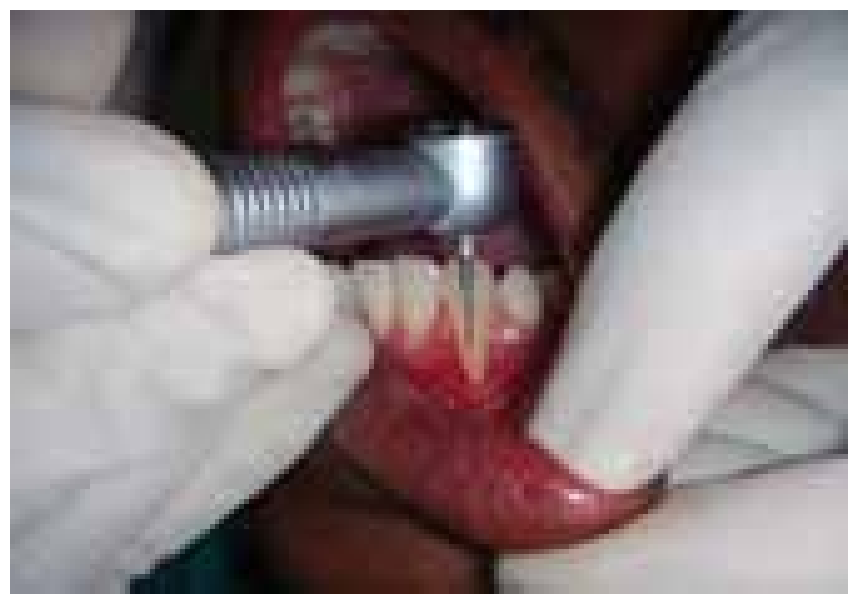

Fig.4 Root prominence reduced

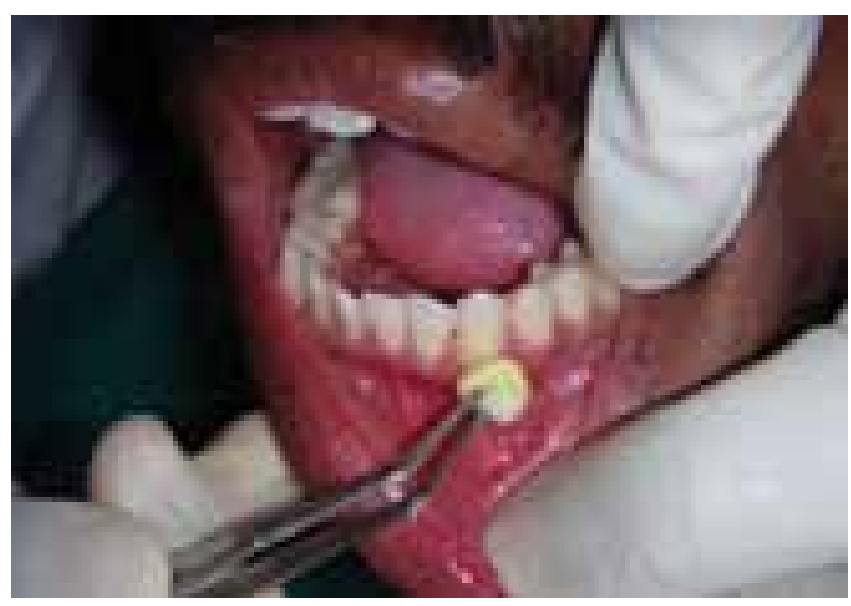

Fig.5 Root Conditioning Done

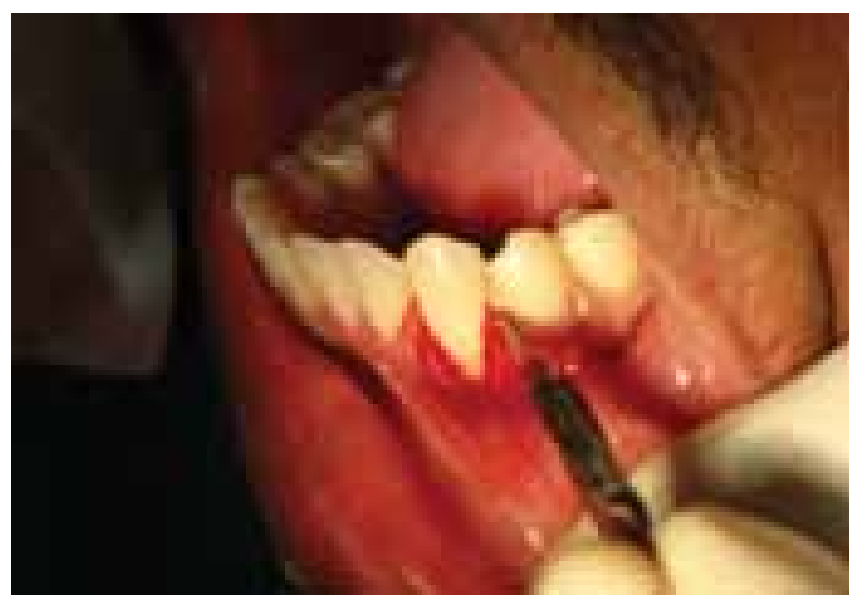

Fig.6: Elimination of the pocket in 33 region

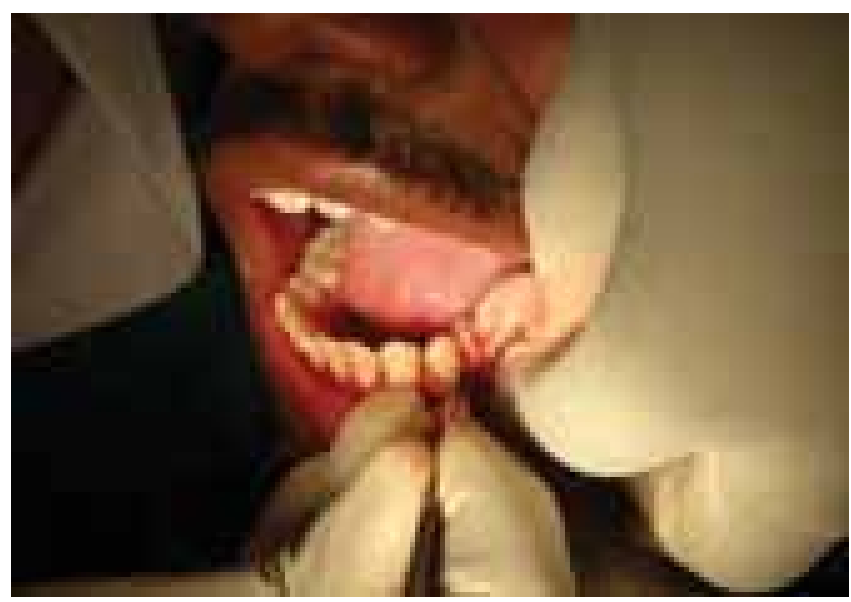

Fig.7: Sulcular incision given 


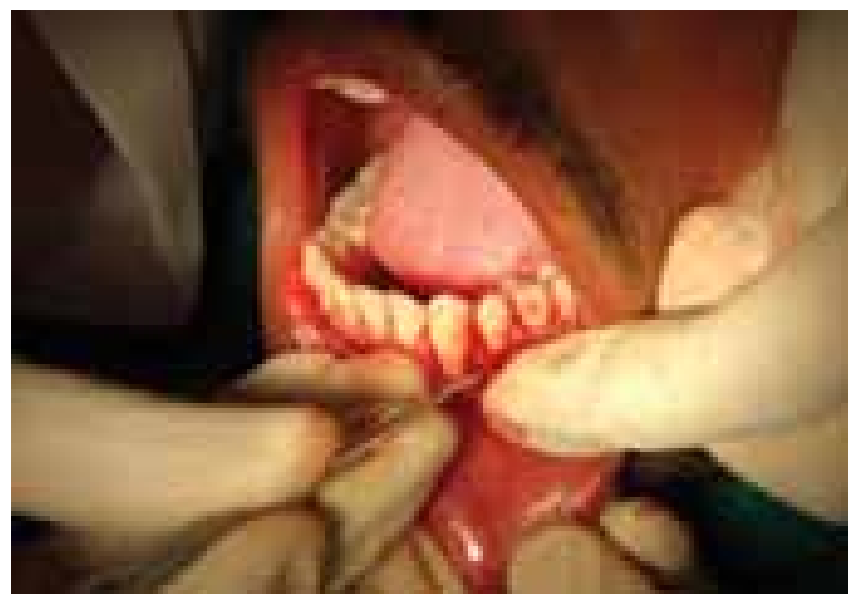

Fig.8: Donor tissue - 34 region

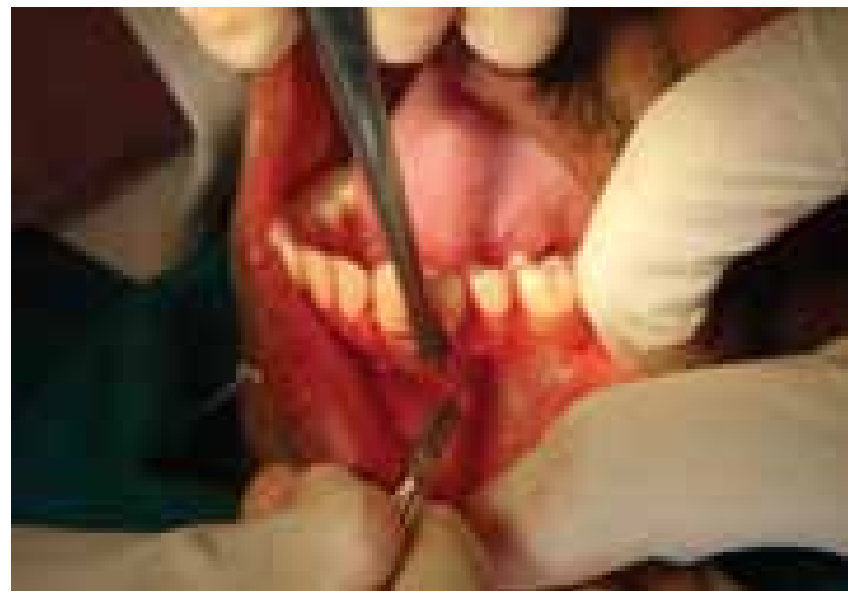

Fig.9: Reflection of the flap

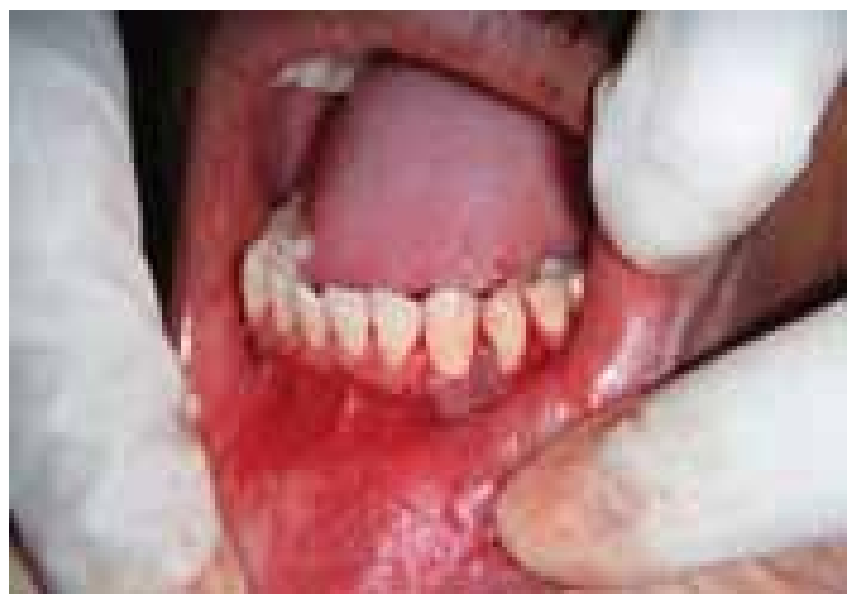

Fig.10: Relieving incision

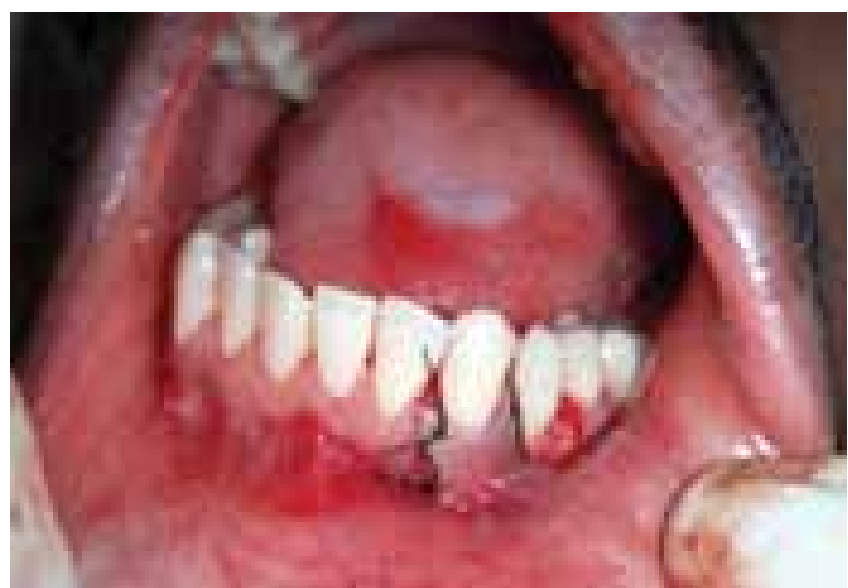

Fig.11: Graft positioned on recipient site

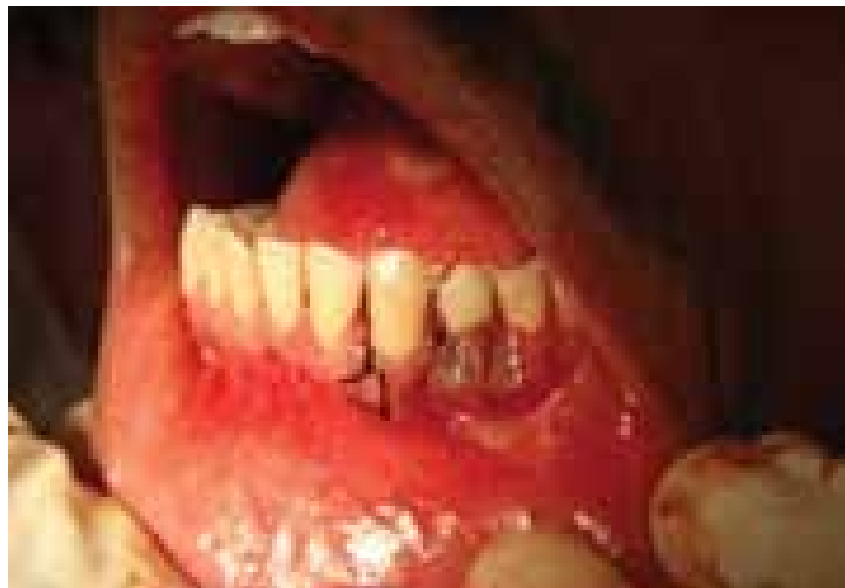

Fig.12: Flap sutured on the recepient site

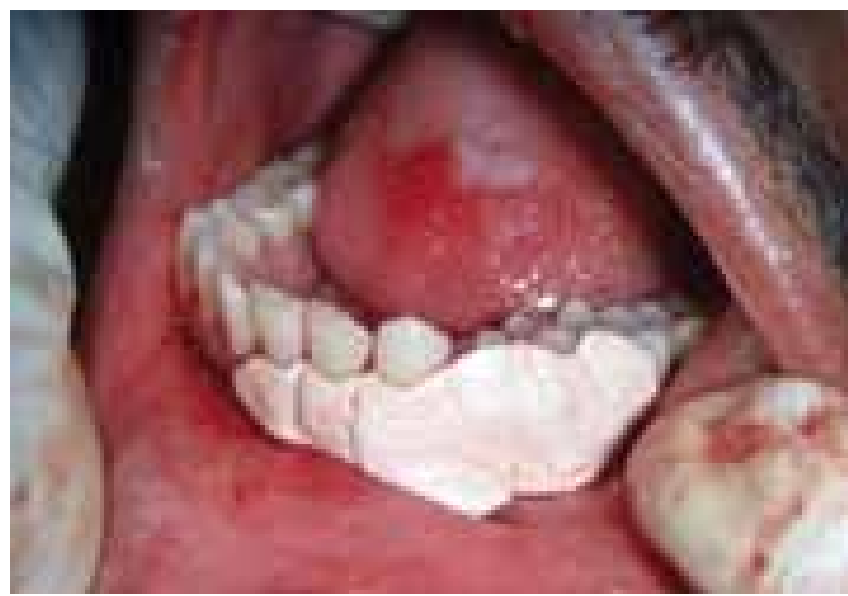

Fig.13: Tin foil adapted over donor site 


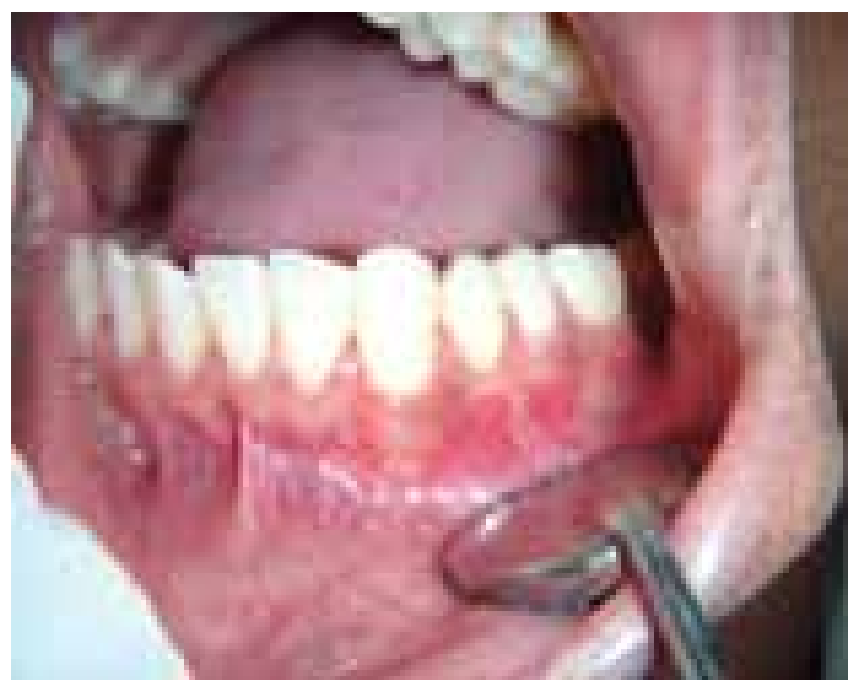

Fig.14: Periodontal dressing given

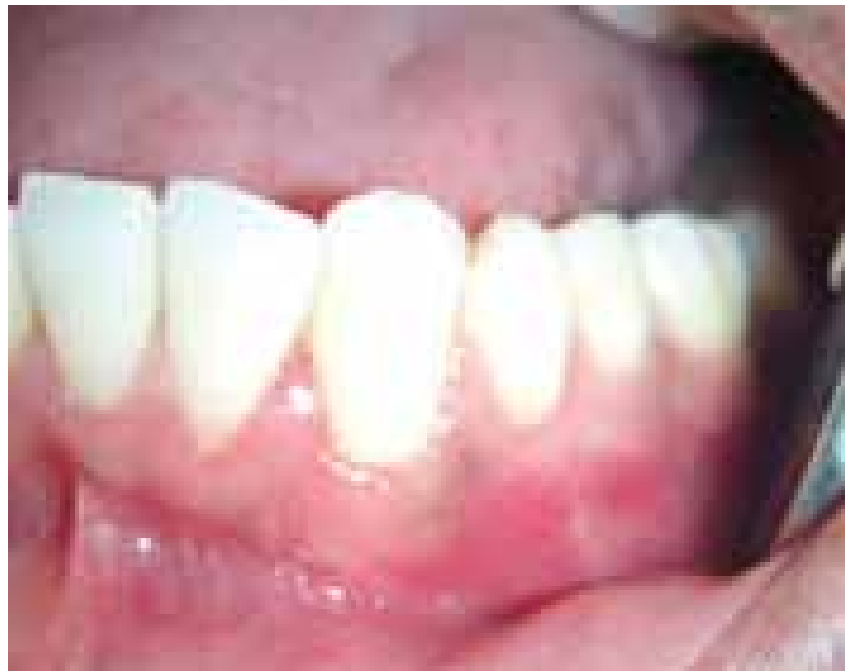

Fig.15: Post-Operative(3 Months)

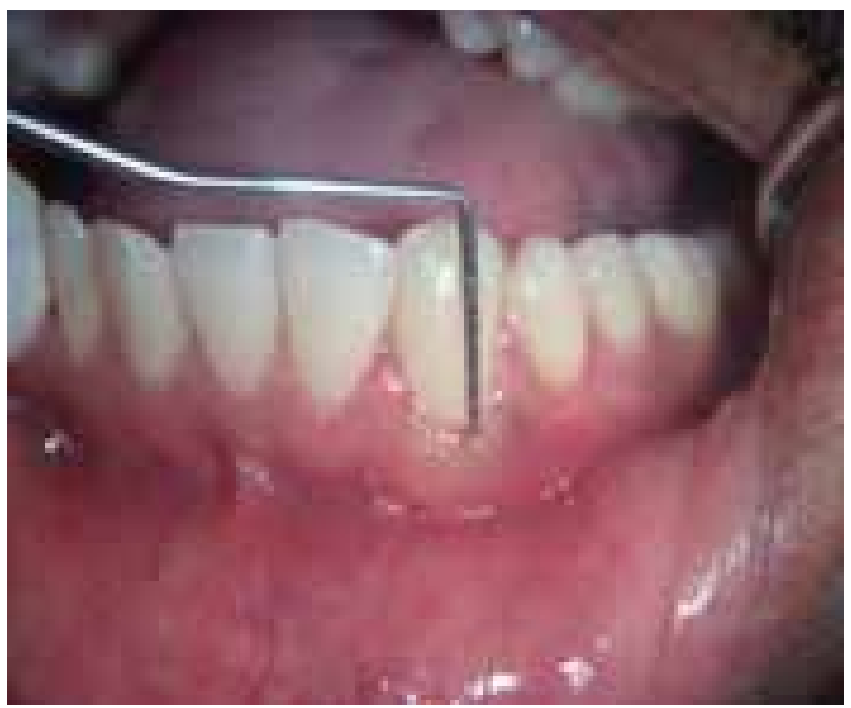

Fig.16: Post-Operative (6 Months)

\section{REFERENCES}

1. Langer B, Langer L. Subepithelial connective tissue graft technique for root coverage. J Periodontol 1985;56:715-20

2. Kassab MM, Cohen RE. Th e etiology and prevalence of gingival recession. J Am Dent Assoc 2003;134:220-5.

3. Martins TM, Bosco AF, Gazoni GG, Garcia SF. Laterally positioned flap associated with subepithelial connective tissue graftfor coverage of isolated gingival recession. RSBO 2011;8:464-8.

4. Newman, Takei, Klokkevold, Carranza. Carranza's Clinical Periodontology A South Asia Edition 2011; 11th edition:volume I, II.

5. Niklaus P. Lang, Jan Lindhe. A clinical periodontology and implant dentistry 2008;5th edition.

6. Pabolu C, Nagubandi KK, Ramisetty A, Mutthinenei RB. Esthetic root coverage with lateral pedicle flap - A case report.J Res Adv Dent 2013;2:11-5.
7. Greenwell H, Bissada NF, Henderson RD, Dodge JR. The deceptive nature of root coverage results. J Periodontol 2000;71:1327-37.

8. Staff leno H. Management of gingival recessions and root exposure problems associated with periodontal disease. Dent Clin North Am 1964;3:111-20.

9. Grupe HE, Warren R. Repair of gingival defects by sliding flapoperation. J Periodontol 1956;27:92-5.

10. Claffey N, Bogle G, Bjorvatn K, Selvig KA, Egelberg J. Topical application of tetracycline in regenerative periodontal surgery in beagles. Acta Odontol Scand 1987;45:141-6.

11. Heinz Erpenstein, Raphael Borchard. Criteria for the selection of root coverage procedures. Part 1: intention, indication, methods. Perio 2006; vol 3,issue 2:139 -152.

12. Guinard, Caffesse. Treatment of localized gingival recessions part III. Comparison of results obtained with lateral sliding and coronally repositioned flaps. J of periodontology 1978; vol 49:457-461. 


\section{Address of Correspondence}

SaiAnusuya G., MDS

corresponding author

Reader,

Department of Periodontics,

Rajas Dental College and Hospital,

Tirunelveli, Tamilnadu, INDIA.

Ph: +91-9487522257

Email:girivaas@gmail.com

\section{Authors:}

${ }^{1}$ Reader, Department of Periodontics, Rajas Dental College and Hospital, Tirunelveli, Tamilnadu, INDIA.

${ }^{2}$ Professor \& HOD, Department of Periodontics, Rajas Dental College and Hospital, Tirunelveli, Tamilnadu, INDIA.

${ }^{3}$ Professor, Department of Periodontics, Krishnadevaraya College of Dental Science and Hospital, Bangalore, Karnataka, INDIA.

${ }^{4}$ Professor, Department of Periodontics, Rajas Dental College and Hospital, Tirunelveli, Tamilnadu, INDIA.

\section{How to cite this article :}

Sai Anusuya G, Jacob Raja S.A, Joann Pauline George, Johnson Raja J. Mucogingival Aesthetic Surgery For An Isolated Denuded Root : A Complete Root Coverage Procedure. Journal of Scientific Dentistry, 2016;6(1):24-29

Source of Support : Nil, Conflicts of Interest : None declared 